\title{
Releasing prophase arrest in zebrafish oocyte: synergism between maturational steroid and Igf1
}

\author{
Debabrata Das, Soumojit Pal and Sudipta Maitra \\ Department of Zoology, Visva-Bharati University, Santiniketan 731235, India \\ Correspondence should be addressed to S Maitra; Email: smaitra3@gmail.com or sudipta.maitra@visva-bharati.ac.in
}

\begin{abstract}
Binding of $17 \beta$-estradiol $\left(E_{2}\right)$ to novel G-protein coupled receptor, Gper1, promotes intra-oocyte adenylyl cyclase activity and transactivates epidermal growth factor receptor to ensure prophase-I arrest. Although involvement of either membrane progestin receptor $(\mathrm{mPR})$ or Igf system has been implicated in regulation of meiosis resumption, possibility of concurrent activation and potential synergism between $17 \alpha, 20 \beta$-dihydroxy-4-pregnen-3-one (DHP)- and Igf-mediated signalling cascades in alleviating $E_{2}$ inhibition of oocyte maturation (OM) has not been investigated. Here using zebrafish (Danio rerio) defolliculated oocytes, we examined the effect of DHP and Igf1, either alone or in combination, in presence or absence of $E_{2}$, on OM in vitro. While priming of denuded oocytes with $E_{2}$ blocked spontaneous maturation, co-treatment with DHP (3 nM) and Igf1 (10 $\mathrm{nM})$, but not alone, reversed $E_{2}$ inhibition and promoted a robust increase in germinal vesicle breakdown (GVBD). Although stimulation with either Igf1 or DHP promoted Akt phosphorylation, pharmacological inhibition of PI3K/Akt signalling prevented Igf1-induced GVBD but delayed DHP action till 4-5 h of incubation.

Moreover, high intra-oocyte cAMP attenuates both DHP and Igf1-mediated OM and co-stimulation with DHP and Igf1 could effectively reverse $\mathrm{E}_{2}$ action on PKA phosphorylation. Interestingly, data from in vivo studies reveal that heightened expression of igf1, igf3 transcripts in intact follicles corresponded well with elevated phosphorylation of Igf1r and Akt, mPRa immunoreactivity, PKA inhibition and accelerated GVBD response just prior to ovulation. This indicates potential synergism between maturational steroid and Igf1 which might have physiological relevance in overcoming $E_{2}$ inhibition of meiosis resumption in zebrafish oocytes.

Reproduction (2016) 151 59-72
\end{abstract}

\section{Introduction}

Oogenesis in teleosts, as in other vertebrates, is under the precise control of neuroendocrine, endocrine and paracrine factors and at gonadal level principally by steroids, estrogens and progestins (Reinecke 2010). In fishes, as in other oviparous vertebrates, estrogens, mainly $17 \beta$-estradiol $\left(E_{2}\right)$, regulate the ovarian growth by hepatic synthesis of the yolk precursor protein, vitellogenin, which is ultimately sequestered by the growing oocytes through receptor-mediated endocytosis (Specker \& Sullivan 1994). At the end of follicular growth, post-vitellogenic gravid oocytes remain arrested at the boundary of G2-M1 of meiotic cell cycle. Prior to ovulation, resumption of meiotic maturation is primarily regulated by the maturation-inducing steroids (MIS), which is $17 \alpha, 20 \beta$-dihydroxy-4-pregnen-3-one (DHP) in majority of the fish species, but 17,20ß,21-trihydroxy-4pregnen-3-one (20 $\beta-S)$ in sciaenids and in marine perciform species (Khan \& Thomas 1999, Nagahama \& Yamashita 2008). Binding of MIS to its membrane progestin receptor (mPRa; Zhu et al. 2003) activates various signal transduction pathways that ultimately culminate in activation of maturation-promoting factor or MPF (Schmitt \& Nebreda 2002). Active MPF promotes progression from meiotic MI-MII through histone $\mathrm{H} 1$ kinase activation, chromosome condensation, spindle formation, germinal vesicle breakdown (GVBD) and release of the first polar body (Nagahama \& Yamashita 2008).

While extensive studies over the past three decades clarified the role of gonadotropin (Lh) and MIS, other hormones such as deoxycorticosterone and testosterone are also effective in regulation of meiotic G2-M1 transition in teleosts (Sundararaj et al. 1979, Nagahama \& Yamashita 2008). Conversely, $\mathrm{E}_{2}$ has been shown as either ineffective or even inhibitory to oocyte maturation (OM) in several teleosts (Jalabert 1975, Sundararaj et al. 1979, Tokumoto et al. 2004). Moreover, $E_{2}$ regulation of ovarian function in zebrafish has been shown to include up-regulation of gonadotropin receptors (Liu et al. 2011) and prevention of precocious OM through maintenance of cell cycle arrest at meiotic G2-M1 boundary (Pang et al. 2008, Pang \& Thomas 2009, 2010). In addition to its role in epidermal growth factor receptor (Egfr) transactivation and MAPK activation, studies in Atlantic croaker and zebrafish oocytes have indicated that binding of $E_{2}$ to its novel G-protein coupled membrane 
receptor Gper, promotes intra-oocyte adenylate cyclase activity and ensures prophase-I arrest (Pang et al. 2008, Peyton \& Thomas 2011). Further, recent evidence demonstrates that catecholestrogen (17 $\beta$-2-hydroxyestradiol) functions as a Gper antagonist and promotes GVBD response in zebrafish by blocking Gper-dependent $E_{2}$ action (Chourasia et al. 2015).

Involvement of local autocrine/paracrine factors in ovarian function has been an area of active research in the recent past (Pang \& Ge 2002, Park et al. 2004, Jamnongjit et al. 2005, Clelland \& Peng 2009, Nelson \& Van Der Kraak 2010a,b, Li et al. 2011, 2015). Specifically, expression of the insulin-like growth factor (Igf) system (i.e. Igf peptides, Igf receptors and Igf binding proteins) and their participation in regulation of ovarian physiology has been reported in teleosts (Reinecke 2010). While igf2 expression has been reported only in granulosa cells of the late stage follicles of tilapia (Schmid et al. 1999), Igf1 mRNA and/or peptide expression has been detected earlier in young and previtellogenic oocytes of red seabream (Kagawa et al. 1995), gilthead seabream (Perrot et al. 2000) and tilapia (Schmid et al. 1999). Interestingly, expression of the gonad-specific Igf3 has been reported mainly in the follicular layer of full-grown oocytes in tilapia and zebrafish (Wang et al. 2008, Nelson \& Van Der Kraak 2010b, Li et al. 2011). Further, human chorionic gonadotropin (hCG) stimulation of igf3 expression in zebrafish full-grown follicles suggests importance of Igfs as local paracrine factors in the ovary (Nelson \& Van Der Kraak 2010b, Li et al. 2011). Moreover, earlier attempts have been made to correlate stages of follicular growth and development with relative abundance of Igf ligands in zebrafish ovary (Nelson \& Van Der Kraak 2010a,b, Li et al. 2011).

Physiological relevance underlying Igf function includes its effects on ovarian steroid production and development of OM competence (Kagawa et al. 1994, Patiño \& Kagawa 1999, Weber \& Sullivan 2000, 2001, Nelson \& Van Der Kraak 2010a). In red seabream, mummichog, striped bass and in southern flounder, Igf1 and/or Igf2 has been shown to exert strong positive influence, albeit with varying intensity, on resumption of meiotic maturation either in denuded oocytes or most notably in intact follicles even in presence of steroidogenesis inhibitors (Kagawa et al. 1994, Negatu et al. 1998, Weber \& Sullivan 2000, Picha et al. 2012). While Igfs alone can induce GVBD, Igf2 has been shown to up-regulate $\mathrm{mPRa}$ and resumption of meiosis providing evidence behind integration of MIS and Igf signalling (Picha et al. 2012). Moreover, isolation of Igf1 $r$ and detection of high affinity Igf1 binding sites in the carp ovary (Maestro et al. 1997), coupled with expression of two different Igf receptor isoforms (Igf1 ra and Igf1 rb) in zebrafish oocyte (Nelson \& Van Der Kraak 2010b) further strengthens the possibility of direct action of Igf on oocyte membrane and regulation of final OM
(Reinecke 2010). Although gonadotropin regulation of major follicular events, e.g., biosynthesis of maturational steroid as well as Igf expression might involve common cellular signalling cascades, such as CAMP/PKA and/or MEK/MAPK (Nagahama \& Yamashita 2008, Li et al. 2011), much less is known about interplay between these pro-maturational factors in teleost ovary.

In addition to the presence of $E_{2}$ in circulation during the periovulatory period, earlier evidence has demonstrated gonadotropin stimulation of $E_{2}$ production by fullgrown ovarian follicles both in vivo and in vitro (Sundararaj et al. 1979, Nelson \& Van Der Kraak 2010a, Sarkar et al. 2014). Moreover, in zebrafish with asynchronous ovarian development, it has been postulated earlier that relatively high level of endogenous estrogen is required to promote vitelloegenesis and to support follicular growth (Pang \& Thomas 2009), which could be sufficiently inhibitory for the daily spawning of this species. While studies in zebrafish have revealed participation of $\mathrm{mPRa}$ in MIS-induced OM that involves rapid activation of $\mathrm{G} \alpha_{i}$ and decrease in cAMP (Hanna etal. 2006, Hanna \& Zhu 2011), we observed involvement of PI3K/Akt signalling pathway is essential for insulininduced OM in this species (Das et al. 2013). Moreover, hCG (analogue of Lh) stimulation of meiosis resumption in zebrafish ovarian follicles in vitro has been shown to require synthesis of maturational steroid, DHP, as well as Igf ligands, mainly Igf3 (Nelson \& Van Der Kraak 2010a, Li et al. 2011, 2015). On the basis of these observations, we reasoned that potential interplay and integration of MISand Igf-mediated signalling pathways might have pivotal influence in overcoming the $E_{2}$-mediated prophase-I arrest in zebrafish oocytes. Our results provide evidence in favour of physiological relevance behind potential synergism between maturational steroid and growth factor (Igf1) action facilitating release of $E_{2}$ inhibition of $\mathrm{OM}$ and accelerated GVBD response in full-grown zebrafish oocytes in vivo and in vitro.

\section{Materials and methods}

\section{Animals}

Sexually mature zebrafish, obtained from local pet stores, were maintained in $60 \mathrm{I}$ glass aquaria, at $28 \pm 1{ }^{\circ} \mathrm{C}$ and $14 \mathrm{~h}$ light: $10 \mathrm{~h}$ darkness cycle with light turned on at $0600 \mathrm{~h}$. Fishes were fed with live blood worms thrice daily and were acclimatized to laboratory conditions for at least 7 days prior to their use in experiments. All animal experiments were carried out following the guidelines of Institutional Animal Ethics Committee of Visva-Bharati University and approved by the committee according to Indian law.

\section{Chemicals and antibody}

Adenylyl cyclase (Ac) inhibitor, SQ22536 and selective inhibitor of Akt, 10-DEBC hydrochloride were obtained from Tocris Bioscience (R\&D Systems, Bristol, UK). Rabbit 
polyclonal anti-MPRA was from Abcam (England, UK); anti-pAkt (Ser473): sc-7985, anti-Akt: sc-8312, anti-p-PKA $\alpha / \beta / \gamma$ cat (Thr198): sc-32968, anti-PKA $\alpha$ cat: sc-903, anti-IGF-IR $\beta$ : sc-713 and mouse monoclonal anti-p-Tyr (PY99): sc-7020 antibodies were from Santa Cruz Biotechnologies. Rabbit monoclonal anti-phospho-Akt (Thr308): \#9275 antibody was from Cell Signalling Technology (Danvers, MA, USA). TRIzol reagent was purchased from Invitrogen, Life Technologies. Unless otherwise specified, hormones, reagents and antibodies were from Sigma-Aldrich. Anti-IGF-IR $\beta$ was raised in rabbit against a peptide mapping at the C-terminus of IGF1R $\beta$ of human origin, which is identical to the corresponding region of zebrafish Igf1 receptor (Maures et al. 2002).

\section{Oocyte preparation and in vitro culture}

For all in vitro experiments, fishes were autopsied in the evening (2000 h) when relatively lower percentage of oocytes matures spontaneously without exogenous stimuli (Hanna \& Zhu 2011). Gravid females $(n=30-40)$ were anesthetized by brief cold shock, decapitated, ovaries excised aseptically and placed immediately in oxygenated zebrafish Ringer $(116 \mathrm{mM}$ $\mathrm{NaCl}, 2.9 \mathrm{mM} \mathrm{KCl}, 1.8 \mathrm{mM} \mathrm{CaCl}$, $5 \mathrm{mM}$ HEPES; pH 7.2) supplemented with penicillin $(100 \mathrm{IU} / \mathrm{ml})$ and streptomycin (100 $\mu \mathrm{g} / \mathrm{ml}$ ) (Kondo et al. 1997). This preparation was also used as incubation medium in future in vitro experiments. The protocol for harvesting post-vitellogenic intact follicles, enzymatic removal of the follicular layer, selection of oocytes divested of surrounding follicular cells and with centrally placed germinal vesicle (GV) were as described earlier (Das et al. 2013). In brief, ovarian follicles were incubated in $\mathrm{Ca}^{2+}$ free zebrafish Ringer's solution containing $0.001 \%$ collagenase type-IA $(1.25 \mathrm{U} / \mathrm{ml})$ for $1 \mathrm{~h}$ at $20 \pm 1{ }^{\circ} \mathrm{C}$ with mild agitation. Follicular cells were removed by repeated $(30 \times)$ gentle pipetting through a narrow pipette $(1 \mathrm{~mm}$ diameter) at $10 \mathrm{~min}$ intervals during incubation. Oocytes showing signs of damage or presence of fibrous amorphous follicle cells (incomplete denudation) were discarded manually. Complete removal of the follicular cells was ascertained by the absence of DAPIpositive nuclei surrounding the denuded oocytes (Peyton \& Thomas 2011, Das et al. 2013) and their inability to undergo OM due to hCG stimulation (Das et al. 2013). Healthy, denuded oocytes of desired size (mean diameter 550$600 \mu \mathrm{m}$ ) were washed thoroughly with fresh zebrafish Ringer and were cultured in a 24-well tissue culture plate (50 oocytes/ well) for the indicated time and hours at $25 \pm 1{ }^{\circ} \mathrm{C}$ under gentle agitation. DHP and $E_{2}$ were dissolved in ethanol and recombinant human IGF1 (Igf1) was dissolved in sterile water. Wortmannin (Wrt, $10 \mu \mathrm{m})$, LY294002 (LY, $25 \mu \mathrm{m})$, 10-DEBC-hydrochloride (DEBC, $5 \mu \mathrm{m})$, forskolin $(1$ and $5 \mu \mathrm{m})$ were dissolved in DMSO and dibutaryl cAMP (dbcAMP, 0.1 and $1 \mathrm{mM}$ ) was dissolved in nuclease free water just before the experiment and added to the culture medium prior to either Igf1 or DHP addition. SQ22536 (SQ; 1-10 $\mu \mathrm{m}$ ) was dissolved in DMSO and was added to the culture medium either alone or in dbcAMP (1 mM)-primed oocytes. The doses of Wrt, LY, DEBC, forskolin and dbcAMP used were as described earlier (Das et al. 2013, Maitra et al. 2014). All chemicals were prepared at 1000 -fold stock and control wells received equal volume of solvent only. Triton X-100 mediated delivery of antiIGF-IR $\beta$ into the oocytes was done according to the method described earlier (Maitra et al. 2014). In brief, Triton X-100 was diluted $(0.1 \%, \mathrm{v} / \mathrm{v})$ with $10 \mathrm{mM}$ PBS; $\mathrm{pH} 7.2$ and sonicated for $1 \mathrm{~min}$ and allowed to complex with anti-IGF-IR $\beta$ antibody $(20 \mu \mathrm{g} / \mathrm{ml})$ for $30 \mathrm{~min}$ each at $25 \pm 1{ }^{\circ} \mathrm{C}$ and at $4{ }^{\circ} \mathrm{C}$. The resultant complex $(10 \mu \mathrm{l})$ was layered on oocytes in culture. Medium was replaced with fresh Ringer after $1 \mathrm{~h}$. Oocyte viability was checked using Trypan blue and GVBD was monitored at $3 \mathrm{~h}$ following immersion in clearing solution (Lessman \& Kavumpurath 1984) under an inverted microscope (Victory FL, Dewinter Optical, Inc., Italy) fitted with phasecontrast optics.

\section{Kinetics of in vivo induction of $\mathrm{OM}$ in gravid females}

Gravid females and adult males were kept separately for at least 7 days prior to their use in the experiment (Westerfield 2000). On the day before sampling, fishes were released at the ratio of one female:two males in $40 \mathrm{I}$ aquaria at $1800 \mathrm{~h}$. Since in this condition females start releasing eggs within 30 min of morning light signaled at $0600 \mathrm{~h}$, the next day females (three to five fish for each time point) were autopsied at 0400, 0500 and $0600 \mathrm{~h}$. Ovaries were removed and full-grown follicles were separated in Ringer's solution by gentle pipetting. Separated follicles were randomly assorted into three groups (200/group) and were processed immediately for preparation of follicular extract, RNA isolation and for determination of relative proportion of oocytes at various stages of maturation and ovulation microscopically. The same experiment was repeated thrice and ovulated eggs were excluded from the present study.

\section{Preparation of oocyte extract}

Denuded oocytes from in vitro study and follicles from in vivo experiment were harvested at appropriate time intervals, washed $(3 \times)$ and homogenised in chilled oocyte extraction buffer (100 mM sodium $\beta$-glycerophosphate, $20 \mathrm{mM}$ HEPES, $15 \mathrm{mM} \mathrm{MgCl}$, $5 \mathrm{mM}$ EGTA, $100 \mu \mathrm{m} \mathrm{p}$-PMSF, $3 \mu \mathrm{g} / \mathrm{ml}$ leupeptin, $1 \mathrm{mM}$ DTT and $1 \mu \mathrm{g} / \mathrm{ml}$ aprotinin; $\mathrm{pH}$ 7.5; Hirai et al. 1992). Supernatant was separated by spinning at $17500 \mathrm{~g}$ for 20 min at $4{ }^{\circ} \mathrm{C}$ and was either used immediately or stored at $-80{ }^{\circ} \mathrm{C}$ until further use.

\section{Electrophoresis, immunoblot analysis and immunoprecipitation}

Following the determination of protein concentration (Lowry et al. 1951), oocyte lysates (50 $\mu \mathrm{g} /$ well) from control and treated groups were resolved in 15\% SDS-PAGE, transferred to Hybond-P PVDF membrane (GE Healthcare Biosciences, Buckinghamshire, UK) using transfer buffer $(25 \mathrm{mM}$ Tris, 193 mM glycine, 20\% methanol; pH 8.5) for $1 \mathrm{~h}$. Membranes were incubated in blocking solution in TBST $(50 \mathrm{mM}$ Tris, $150 \mathrm{mM} \mathrm{NaCl}, 0.1 \%$ Tween-20; $\mathrm{pH}$ 7.6) containing 5\% BSA overnight at $4{ }^{\circ} \mathrm{C}$, incubated in primary antibody diluted (1:500) in blocking buffer for $4 \mathrm{~h}$ at room temperature, washed with TBST $(3 \times)$ and incubated in alkaline phosphatise tagged anti-rabbit IgG $(1: 1000)$. Bands were developed 
by adding BCIP-NBT, recorded in Gel Doc apparatus (Bio-Rad) and imported into Adobe Photoshop. Band intensities were quantified using the freely available Imagej Software and expressed as an arbitrary unit.

For immunoprecipitation, $\sim 100 \mu \mathrm{g}$ of the proteins from zebrafish ovarian follicles were incubated overnight at $4{ }^{\circ} \mathrm{C}$ with $1 \mu \mathrm{g}$ of anti-IGF-IR $\beta$ antibody. Around $50 \mu \mathrm{l}$ of protein A agarose (Pierce, Thermo Scientific, Rockford, IL, USA) was added to each tube and incubated with gentle mixing for $2 \mathrm{~h}$ at room temperature followed by addition of $500 \mu$ of IP buffer (25 mM Tris, $150 \mathrm{mM} \mathrm{NaCl} ; \mathrm{pH}$ 7.2) and centrifugation at $2500 \mathrm{~g}$ for $3 \mathrm{~min}$ at $4{ }^{\circ} \mathrm{C}$. The supernatant was discarded and this step was repeated two more times. Immunoprecipitates were boiled in $5 \times$ SDS sample buffer and resolved in $15 \%$ SDS-PAGE then transferred to Hybond-P PVDF membrane followed by primary and secondary antibody incubation and colour development as described previously in immunoblot analysis.

\section{Total RNA extraction, CDNA synthesis and RT-PCR}

Total RNA was extracted from ovarian follicles $(\sim 200$ follicles/time group from three different donor fish) using TRIzol reagent according to the manufacturer's protocol. RNA pellet was reconstituted in 20-30 $\mu$ l of nuclease free water (Fermentas, GENETIX, New Delhi, India), followed by quantification using a NanoDrop 2000 Spectrophotometer (Thermo Scientific, Waltham, MA, USA). Integrity of the RNA samples (A260/280 between 1.8 and 2.2) was checked electrophoretically in denaturing agarose gel followed by ethidium bromide staining. One microgram of total RNA from each sample was reverse transcribed using Verso RT cDNA Synthesis Kit (\#AB1453, Thermo Scientific) at $42{ }^{\circ} \mathrm{C}$ for $1 \mathrm{~h}$ in $20 \mu$ reaction mix containing cDNA synthesis buffer, anchored oligo dT primer, deoxyNTPs, nuclease free water, RT enhancer and verso RT with significantly attenuated RNase $\mathrm{H}$ activity. In order to rule out the possibility of DNA contamination, $\mathrm{RT}(-)$ samples containing all other components previously mentioned, except RT, were prepared in parallels. Gene-specific primers for lgf receptor isoforms, and mpra (Table 1) were used for PCR amplification taking $1 \mu \mathrm{l}$ of RT product (template cDNA) in a final reaction volume of $25 \mu \mathrm{l}$ using $2 \times$ PCR master mix (\#K0171, Fermentas) containing Taq polymerase, dNTPs and $\mathrm{MgCl}_{2}$. After an initial denaturation step for $3 \mathrm{~min}$ at $95{ }^{\circ} \mathrm{C}$, PCR amplification was carried out in Veriti 96-Well Thermal Cycler (Applied Biosystems) with the cycling profile of $30 \mathrm{~s}$ at $94{ }^{\circ} \mathrm{C}, 30 \mathrm{~s}$ at $52-56{ }^{\circ} \mathrm{C}$ (depending on the primer sets used), $30 \mathrm{~s}$ at $72{ }^{\circ} \mathrm{C}$ for 30 cycles followed by a final extension for $10 \mathrm{~min}$ at $72{ }^{\circ} \mathrm{C}$. Amplified products were electrophoresed on $2 \%$ agarose gels along with $100 \mathrm{bp}$ DNA ladder (Fermentas) and visualized by ethidium bromide staining. PCR amplification of $b$-actin was used as an internal loading control.

\section{Real-time quantitative PCR}

Real-time quantitative PCRs were set up in a 7500 Real-Time PCR System (Applied Biosystems) using gene-specific primers from earlier reports (Table 1). For both target and reference genes, reaction mix (final volume: $20 \mu \mathrm{l}$ ) contained $2 \mu \mathrm{l}$ of
Table 1 List of zebrafish oligonucleotide primers and their accession numbers used in the semi-quantitative RT-PCR assay.

\begin{tabular}{|c|c|c|}
\hline Gene & Sequence $\left(5^{\prime}-3^{\prime}\right)$ & Accession no. \\
\hline \multirow[t]{2}{*}{$i g f 1^{\text {a }}$} & F: CAGCAAACCGACAGGATATGG & NM_131825 \\
\hline & R: CAGCTCTGAAAGCAGCATTCG & \\
\hline \multirow[t]{2}{*}{$\operatorname{igf} 2 a^{a}$} & F: CGCCTGCCATGGATGATTAC & NM_131433 \\
\hline & R: TCAGTGAGCGCATCGTTGTT & \\
\hline \multirow[t]{2}{*}{$\operatorname{igf} 2 b^{\mathrm{a}}$} & F: AACCTGCCAAGTCAGAGAGGG & NM_001001815 \\
\hline & R: GGACCTCCTGTTTTAATGCGG & \\
\hline \multirow[t]{2}{*}{$i g f 3^{a}$} & F: ACGCTGCGGACGAGAACTAG & NM_001115050 \\
\hline & R: GCTGCTCCAGGTTTGCCTAT & \\
\hline \multirow[t]{2}{*}{ igf1ra } & F: АСТСАТАСТСTGGGСTCTCTGTCC & NM_152968 \\
\hline & R: TGCGTATGTATTATCCACAAGCTCTT & \\
\hline \multirow[t]{2}{*}{ igf1rb $b^{\mathrm{a}}$} & F: ATCCTCCCGGCCTTACTGTT & NM_152969 \\
\hline & R: CCTGTCATTGTTTCGGTTCTTGT & \\
\hline \multirow[t]{2}{*}{$m p r a^{\mathrm{b}}$} & F: CATGGCTTCCGGTTAATTGTC & AY149121 \\
\hline & R: GCCCAATCTGCTCCATCAC & \\
\hline \multirow[t]{2}{*}{$b$-actin ${ }^{c}$} & F: GGTATGGGACAGAAAGACAG & NM_181601 \\
\hline & R: AGAGTCCATCACGATACCAG & \\
\hline
\end{tabular}


Callard (2001).

sample cDNA template diluted (1:10) with nuclease-free water, forward and reverse primers (250 $\mathrm{nM}$ of each) and SYBR Green PCR Master Mix (SYBR Green Dye, dNTPs, passive reference I, AmpliTaq Gold DNA Polymerase; Applied Biosystems). PCR conditions were optimized to generate $>95 \%$ efficiency. After an initial enzyme activation step at $95{ }^{\circ} \mathrm{C}$ for $10 \mathrm{~min}$, the amplification reaction was carried out for 40 cycles with the cycling profile of $95{ }^{\circ} \mathrm{C}$ for $15 \mathrm{~s}, 52{ }^{\circ} \mathrm{C}$ for $30 \mathrm{~s}$ and $72{ }^{\circ} \mathrm{C}$ for $30 \mathrm{~s}$. Melt curve analyses were performed at the end of reaction to check specific amplification of the target. Each sample was run in triplicate and the $C T$ value was corrected using corresponding endogenous control, $b$-actin gene and calculations were based on the $2^{-\Delta \Delta C T}$ method (Livak \& Schmittgen 2001).

\section{Statistical analysis}

The ratio between expression levels of igf1, igf $2 a$, igf $2 b$ and igf 3 to that of $b$-actin (internal control) were calculated and expressed as fold change compared with the reference group. All results are mean \pm s.E.M. of at least three independent experiments using oocytes from different donor fish. Data were analyzed by one-way ANOVA $(P<0.001)$, followed by Duncan's post hoc test for multiple group comparisons, $P<0.05$ was considered as statistically significant.

\section{Results}

\section{$E_{2}$ inhibition of spontaneous maturation in denuded zebrafish oocyte}

Priming with graded levels of $E_{2}$ (1-1000 nM) could successfully block spontaneous maturation in dose- and duration-dependent manner in denuded oocytes in vitro (Fig. 1A and B). Further, as shown in Fig. 1B (inset), negligible or very low levels of p-ERK1/2 was detected 
A
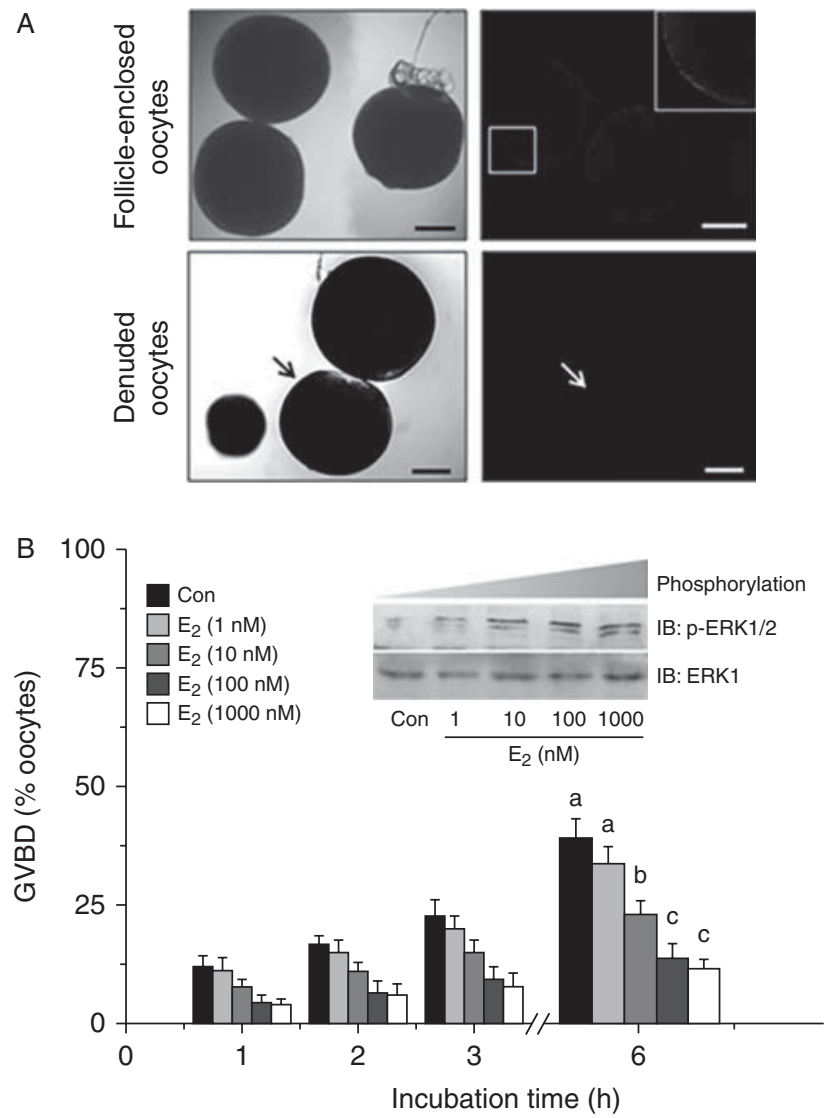

Figure 1 Effect of $17 \beta$-estradiol inhibition on spontaneous maturation and ERK1/2 phosphorylation. Representative photomicrographs of intact ovarian follicles (upper panel) compared to the surface images of denuded oocytes (lower panel) viewed through light (left) or fluorescent microscopy (right) after staining with DAPI (A), inset, follicular cell nuclei stained positive for DAPI are shown at higher magnification. Solid arrows indicate selection of post-vitellogenic denuded oocytes of desired size class $(\sim 550-600 \mu \mathrm{m})$ used in the present study, scale bar $\sim 200 \mu \mathrm{m}$. Denuded oocytes were treated either with graded levels of $E_{2}(1-1000 \mathrm{nM})$ or not (control), GVBD were scored at indicated time intervals and expressed in percent (B). Results are mean \pm s.E.M. of three independent experiments. Data were analyzed by one-way ANOVA $(P<0.001)$ and Duncan's test $(P<0.05)$. Groups with same lowercase letter are not significantly different and those with different letters differ significantly. Oocyte lysates $(30 \mathrm{~min})$ of indicated dose groups were analyzed by SDS-PAGE and subjected to immunoblot analysis using phospho-specific anti-ERK $1 / 2$ antibody that specifically recognise the activated form of the protein (inset, B). Anti-ERK1 immunoblot served as internal loading control. Data are representative of two independent experiments with identical results.

in unstimulated control and $1 \mathrm{nM} \mathrm{E}_{2}$-treated groups (inset, lanes 1 and 2, Fig. 1B). However, significant increase in p-ERK1/2 was observed due to either 10 or $100 \mathrm{nM}$ of $E_{2}$ as early as 30 min of incubation (inset, lanes 3 and 4, Fig. 1B). Further, compared to $100 \mathrm{nM} \mathrm{E}_{2^{-}}$ treated group, no significant variation in GVBD response and ERK1/2 phosphorylation was observed due to $1000 \mathrm{nM} \mathrm{E}_{2}$ (Fig. 1B). On the preceding basis, two different doses of $E_{2}$, i.e., 10 and $100 \mathrm{nM}$ were selected for subsequent experiments.

\section{Effect of DHP- and Igf1-stimulation on $E_{2}$-mediated prophase arrest}

Though co-treatment with hCG and Igf1 could trigger significant increase in synthesis of DHP in zebrafish ovary (Nelson \& Van Der Kraak 2010a), possibility of any synergistic action between maturational steroid- and lgfmediated signalling cascades in alleviating $\mathrm{E}_{2}$-mediated prophase arrest has not been investigated earlier. In order to test this possibility, we examined GVBD response due to DHP and Igf1, either alone or in combination, in presence or absence of $E_{2}$. While DHP and Igf1 could trigger GVBD response in a dose-dependent manner (Fig. 2A), priming of denuded oocytes with $E_{2}$ (10 and $100 \mathrm{nM}$ ) could attenuate spontaneous maturation and prevent either DHP (3 nM) or Igf1 (10 nM)-mediated GVBD response significantly $(P<0.01$; Fig. $2 \mathrm{~B})$. More importantly, co-treatment with very low doses of DHP and Igf1 (at 3 and $10 \mathrm{nM}$ respectively) for $3 \mathrm{~h}$, could trigger a robust increase in meiotic $\mathrm{G} 2-\mathrm{M} 1$ transition either in absence or in presence of $\mathrm{E}_{2}$ (Fig. 2B) and the data was comparable to the GVBD response either due to DHP (30 or $300 \mathrm{nM})$ or Igf1 $(100 \mathrm{nM})$ at $3 \mathrm{~h}$ of incubation (Fig. 2A), indicating possibility of an additive
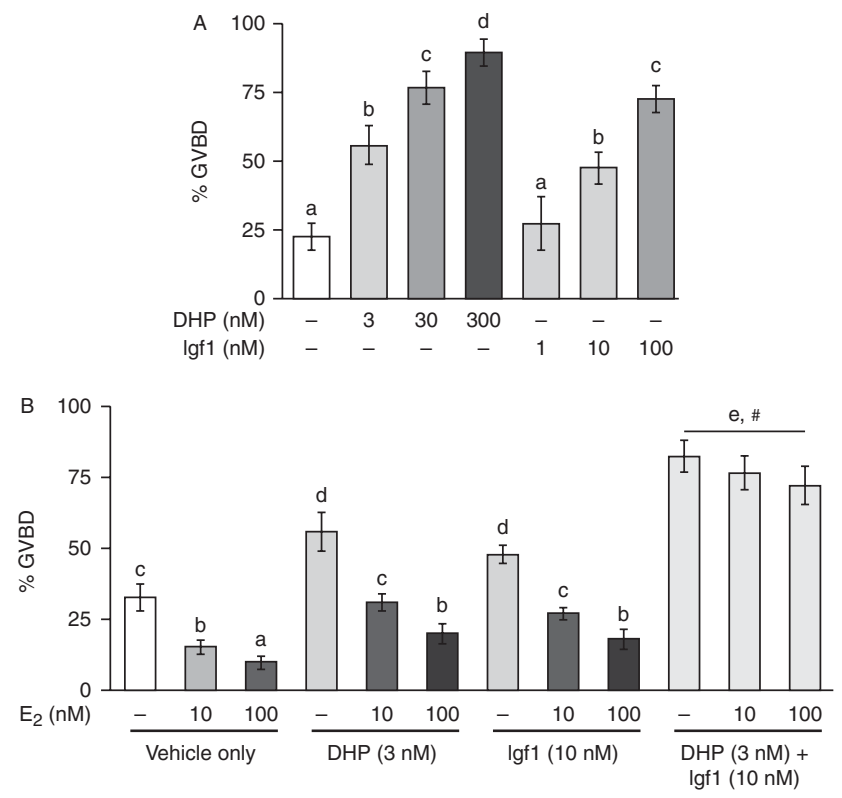

Figure 2 Effect of a $3 \mathrm{~h}$ treatment with maturational steroid (DHP) and insulin-like growth factor 1 (Igf1) on $17 \beta$-estradiol $\left(\mathrm{E}_{2}\right)$-induced meiotic prophase-l arrest in vitro. Defolliculated zebrafish oocytes were primed with $E_{2}(10$ and $100 \mathrm{nM})$, followed by stimulation either without or with increasing concentration of DHP (A) and Igf1 (B), either alone or in combination (C), and scored for GVBD. Data (mean \pm s.E.M.) of at least three independent experiments from different donor fish were analyzed by one-way ANOVA $(P<0.001)$ and Duncan's post hoc test $(P<0.05)$. Groups with same lowercase letter above the bars are not significantly different and those with different letters differ significantly; ${ }^{\#} P<0.01$ compared to groups with or without $\mathrm{E}_{2}$ stimulation. 


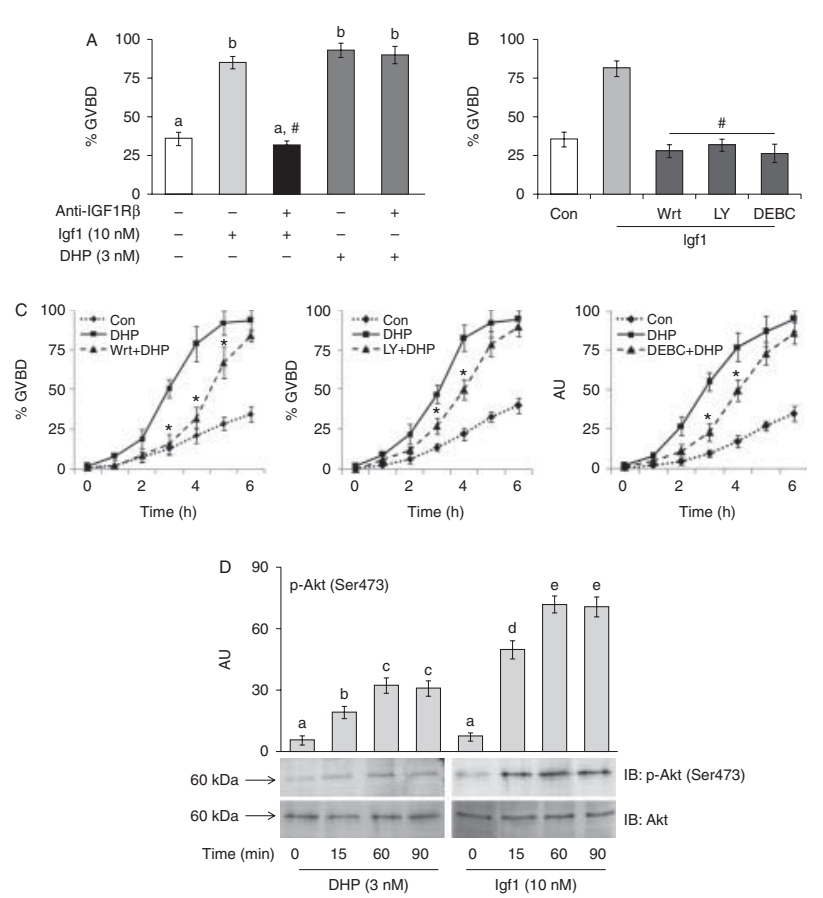

Figure 3 Inhibition of Igf1-, but not DHP-induced oocyte maturation $(3 \mathrm{~h})$ in IGF1R $\beta$ immunodepleted cells (A) and (B) PI3K/Akt regulation of Igf1 - and (C) maturational steroid-induced GVBD response.

Denuded zebrafish oocytes primed with either Wrt $(10 \mu \mathrm{M})$, LY $(25 \mu \mathrm{M})$ or DEBC $(5 \mu \mathrm{M})$ or not (Con, vehicle only), were stimulated with either with Igf1 $(10 \mathrm{nM})$ till $3 \mathrm{~h}$ or DHP $(3 \mathrm{nM})$ till $6 \mathrm{~h}$ and GVBD was scored microscopically. Oocyte lysates from control and treated groups were subjected to immunoblot analysis using anti-p-Akt (Ser473) antisera that specifically recognize active form of Akt, phosphorylated at Ser473, anti-Akt immunoblot served as loading control (D). Corresponding densitometric analysis are shown above the immunoblot, values are mean \pm S.E.M. and are analyzed by one-way ANOVA followed by Duncan's multiple range test, ${ }^{\#} P<0.001$ against Igf1treated and $* P<0.05$ against DHP-stimulated group of respective time intervals. Groups with same lowercase letter above the bars are not significantly different and those with different letters differ significantly. Immunoblot data are representative of at least three separate experiments from different donor fish showing identical results.

influence by two altogether separate signalling pathways leading to withdrawal of prophase arrest and resumption of meiotic maturation.

\section{Relative importance of PI3K/Akt signalling on DHP and Igf-induced GVBD response}

Regulation of intra-oocyte signalling events by DHP and Igf1 was investigated. Pre-incubation with anti-IGF-IR $\beta$ antibody could prevent Igf1, but not DHP-induced GVBD response (Fig. 3A). Further, pharmacological inhibition of PI3K/Akt signalling, by either 10-DEBC hydrochloride, a selective Akt inhibitor or by two mechanistically different and highly selective PI3K inhibitors, Wrt and LY, attenuates Igf1-induced OM significantly $(P<0.01$; Fig. 3B). Interestingly, priming with either LY or DEBC could delay maturational steroid-induced GVBD response till 4-5 h of incubation (middle and right panels, Fig. 3C) and Wrt in particular almost completely blocked DHP action on OM up to $3 \mathrm{~h}$ (left panel, Fig. 3C). Immunoblot analyses revealed that while priming with Igf1 $(10 \mathrm{nM})$ promoted a significant increase in phospho-Akt (Ser473) as early as $15 \mathrm{~min}$ that reached the peak level between 60 and 90 min of incubation (right panel, Fig. 3D), appreciable increase in Akt phosphorylation (activation) was observed at $60 \mathrm{~min}$ of DHP (3 nM) stimulation (left panel, lane 3, Fig. 3D).

\section{Effect of cAMP/PKA regulation of DHP and/or Igf1 induced meiotic G2-M1 transition}

In teleosts, high intra-oocyte cAMP is considered as a pre-requisite for prophase-I arrest and attenuate MIS action on OM in a variety of teleosts species (DeManno \& Goetz 1987, Haider \& Baqri 2002, Khan \& Maitra 2013). Next we examined effects of Ac inhibition or CAMP modulators on spontaneous maturation and DHP/lgf1-mediated GVBD response. As shown in Fig. 4A, priming with Ac inhibitor, SQ22536 alone
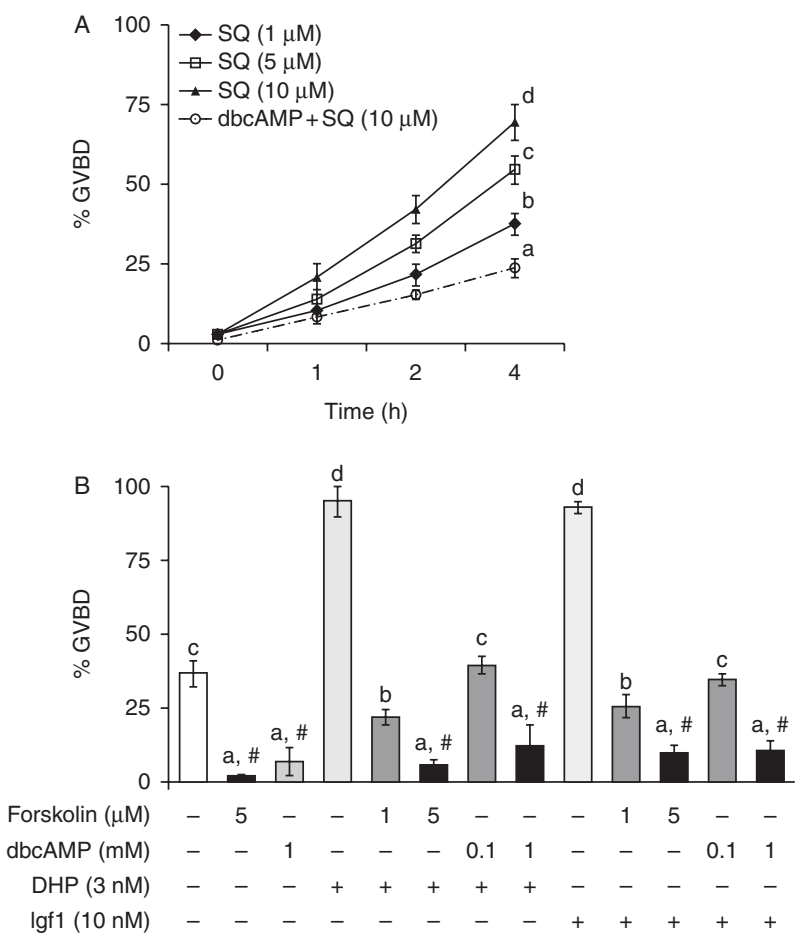

Figure 4 cAMP regulation of GVBD response in zebrafish oocytes. Defolliculated zebrafish oocytes were primed with either cell permeable dbcAMP or adenylyl cyclase (Ac) activator forskolin or not followed by stimulation with either increasing concentration of $A c$ inhibitor SQ22356 (A) or Igf1/DHP (B) and scored for GVBD at $4 \mathrm{~h}$. Values are mean \pm S.E.M. of three independent experiments. Data are analyzed by one-way ANOVA followed by Duncan's multiple range test. Groups with same lowercase letter above the bars are not significantly different and those with different letters differ significantly; ${ }^{\#} P<0.001$ compared to Igf1- or DHP-stimulated group. 
could promote meiotic maturation. In contrast, forced elevation of intra-oocyte cAMP by either forskolin or dbcAMP could abrogate DHP or Igf1 action in a dose-dependent manner (Fig. 4B).

Since high cAMP represents counter-regulatory action on DHP- and Igf1-mediated meiotic maturation, participation of PKA was hypothesized. The catalytic sub-unit of PKA remain phosphorylated on its activation loop (phospho-PKAc) allowing proper substrate recognition and catalysis (Moore et al. 2002). In the present study, endogenous PKA activity was assessed indirectly by immunoblot analysis using $\mathrm{p}-\mathrm{PKA} \alpha / \beta / \gamma$ cat (Thr198) antibody (Khan \& Maitra 2013, Maitra et al. 2014). As shown in Fig. 5A, elevated phosphorylation of PKA (active) was detected in un-stimulated control (lane 1 ) as well as in oocytes primed with graded levels of $E_{2}$ (lanes 2, 3 and 4). Although stimulation with either DHP (3 nM) or Igf1 (10 nM) was sufficient to promote p-PKAc dephosphorylation (inactivation) (lanes 5 and 6, Fig. 5A), pre-incubation with $E_{2}$ (at both 10 and $100 \mathrm{nM}$ ) could significantly reverse DHP- or Igf1 action on PKA inhibition (lanes 8, 9, 11 and 12, Fig. 5A). Further, co-treatment with DHP and Igf1 could rescue negative regulation by $E_{2}$, at both the dose levels tested, as evident from rapid dephosphorylation of p-PKAc (lanes 10 and 13, Fig. 5A) indicating the pivotal influence of active PKA in the maintenance of $E_{2}$-mediated prophase-I arrest and involvement of both maturational steroid and Igf1 in rapid dephosphorylation of p-PKAcat in maturing oocyte. More importantly, the time kinetics data reveal that co-treatment with DHP and Igf1, but not alone, could successfully reverse negative regulation by $E_{2}$ and promoted accelerated GVBD response at all the time points tested (lower panel, Fig. 5B). This suggests an additive influence of the two disparate signalling strategies which might lead to withdrawal of prophase arrest and resumption of meiotic maturation in this species. Interestingly, no significant variation in GVBD response was observed due to co-stimulation with DHP and Igf1 in oocytes either primed or not with two different doses of $E_{2}$ (Fig. 5B).

\section{Expression profile and phosphorylation status of molecular markers associated with in vivo $O M$}

Since co-treatment with DHP/lgf1 was more potent in overcoming $E_{2}$ inhibition of $O M$ and also triggered rapid dephosphorylation of phospho-PKA in vitro, next we examined the physiological relevance of potential involvement of maturational steroid and growth factormediated events in withdrawal of meiotic arrest in gravid females in vivo. Ovaries were harvested at three different time intervals just prior to ovulation, with spawning induced in the laboratory condition (Fig. 6A). Follicles were separated manually and assayed for transcript abundance for igf ligands (igf1, igf2a, igf $2 b$ and igf3) through qRT-PCR in relation to relative proportion of oocytes undergoing GVBD in vivo. Further, presence of Igf receptor (igf1 ra and igf1rb) and mpra transcripts was checked by semi-quantitative RT-PCR and immunoblot analyses were performed to detect anti-mPRa immunoreactive protein as well as phosphorylation status of Igf1 r $\beta$, Akt and PKA using phospho-specific antibodies.

As shown in Fig. 6, while at $0400 \mathrm{~h}(-2 \mathrm{~h}$ of light signal on), ovaries contained mainly GV intact (immature) oocytes; substantial increase in percentage of
A

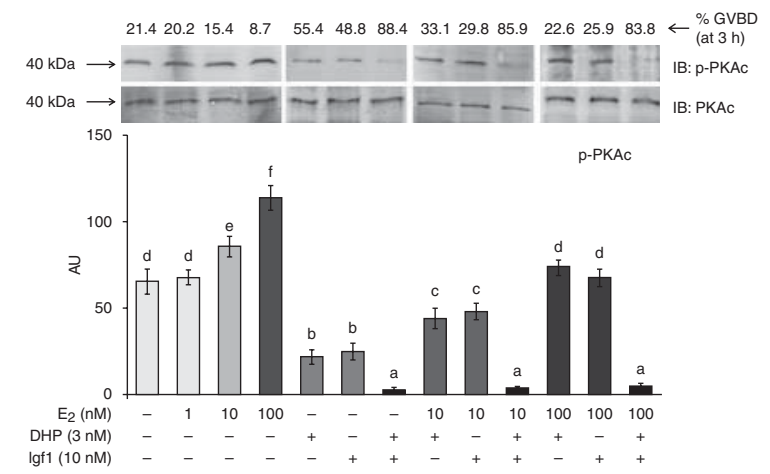

B


Figure 5 Effect of DHP $(3 \mathrm{nM})$ and Igf1 $(10 \mathrm{nM})$ stimulation, either alone or in combination, on $E_{2}(10$ and $100 \mathrm{nM})$ action on PKA phosphorylation (A) and kinetics of meiotic $\mathrm{G} 2-\mathrm{M} 1$ transition (B) in vitro. Oocyte lysates from indicated groups and time intervals were subjected to immunoblot analyses with anti-p-PKA $\alpha / \beta / \gamma \mathrm{c}$ (Thr198) antibody that recognizes the catalytic sub-unit of PKA phosphorylated on its activation loop. Anti-PKAac immunoblot served as loading control. Corresponding densitometric analysis are shown below the immunoblot, values are mean \pm s.E.M. of three independent experiments. Data are analyzed by one-way ANOVA followed by Duncan's multiple range test. Groups with same lowercase letter above the bars are not significantly different and those with different letters differ significantly; $* P<0.05$ compared to $10 \mathrm{nM}$ and ${ }^{\#} P<0.001$ compared to 10 or $100 \mathrm{nM}$ $E_{2}$-treated groups. 

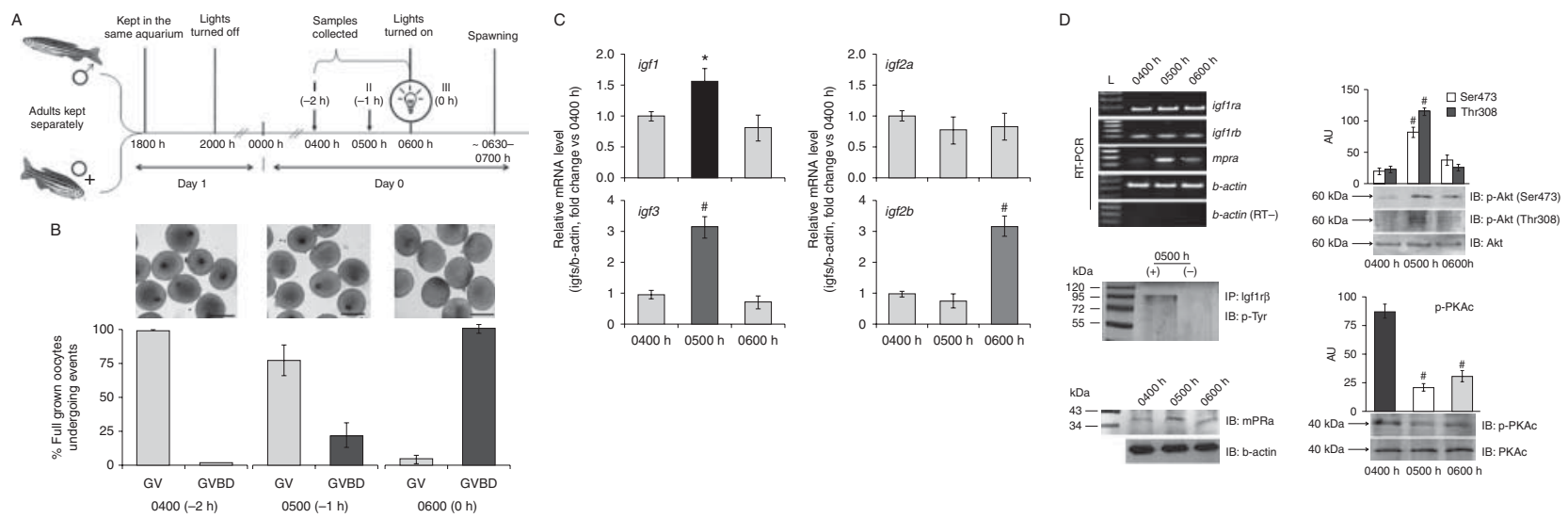

Figure 6 Schematic representation of induction of captive breeding in gravid females (A). Relative proportion of immature (GV intact) and maturing oocytes (undergoing GVBD) in vivo (B). Data are mean \pm s.E.M.; $n=3$ experiments with three to five females for each time point per experiment. Representative photomicrograph of follicle-enclosed oocytes in clearing solution (upper panel, B) at indicated time points. Scale bar $500 \mu \mathrm{m}$. RNA samples from ovarian follicles ( $\sim 200$ follicles/time point from three to five different donor fish) were reverse transcribed and transcript abundance for Igf ligands (igf1, igf2a, igf2b and igf3) was checked through qRT-PCR; $b$-actin served as endogenous control (C). Values are the mean \pm s.E.M. of three separate experiments as mentioned earlier. Ovulated eggs were excluded from the present study. Besides, expression of igf $1 \mathrm{ra}$, igf1 rb and $m p r a$ (left upper, D) was checked through semi-quantitative RT-PCR at indicated time points. RT(-): RNA without RT; L, DNA ladder. Further, protein samples extracted from intact follicles harvested at various time points prior to onset of ovulation, was incubated either without ( - ) or with anti-IGFIR $\beta$ antibody (+), followed by probing with anti-p-Tyr antibody (left middle, D) or subjected to immunoblot analysis using anti-mPRa (left lower, D), anti-p-Akt (both Ser473 and Thr308) (right upper, D) and anti-p-PKA $/ / \beta / \gamma \mathrm{C}$ antibody (right lower, D). Anti-b-actin, anti-Akt and anti-PKA $\alpha \mathrm{C}$ immunoblot served as internal loading control. Corresponding densitometric analysis are also shown above the immunoblot; values are mean \pm S.E.M. of three independent experiments. Data were analyzed by one-way ANOVA and Duncan's multiple range test; ${ }^{*} P<0.05$ and ${ }^{\sharp} P<0.001$ compared to data at $-2 \mathrm{~h}$ of light signal on at $0400 \mathrm{~h}$.

oocytes undergoing GV migration and GVBD was observed at $0500 \mathrm{~h}(-1 \mathrm{~h}$; Fig. 6B). Moreover, at $0600 \mathrm{~h}(0 \mathrm{~h})$, i.e., at the time of light signals were on, more than $90 \%$ of oocytes underwent GVBD (Fig. 6B).

Although there was a significant $(P<0.01)$ increase in transcript for igf1 and igf3 (1.5- and 3 folds respectively) at $0500 \mathrm{~h}(-1 \mathrm{~h})$, igf 2 a did not undergo any significant change at indicated time intervals (Fig. 6C). In contrast, a sharp increase was noticed in igf $2 b$ at $0600 \mathrm{~h}$ (Fig. 6C) when the majority of the oocytes completed G2-M1 transition (Fig. 6B) and ovaries were filled with oocytes arrested at MII stage (data not shown).

While at all three sampling hours, transcripts for igf1 rs and mpra were detected in isolated follicles, albeit in varying amounts, immunoblot analysis revealed elevated $\mathrm{mPRa}$ at protein level and Tyr phosphorylation of the anti-Igf1 $\mathrm{r}$ immune-precipitate at $0500 \mathrm{~h}(-1 \mathrm{~h}$; left panel, Fig. 6D). Besides, dual phosphorylation of Akt at Ser473 and Thr308 concomitant with marked dephosphorylation of phospho-PKAcat (right panel, Fig. 6D) correlated well with elevated GVBD response (Fig. 6B) during this time in vivo.

\section{Discussion}

Prophase-I arrest and its timely release play major roles to accomplish follicular growth, acquisition of maturational competence and production of fertilizable female gametes. Earlier $E_{2}$ has been shown to prevent growing oocytes to mature precociously and binding of $E_{2}$ to its cognate cell surface receptor Gper was implicated in maintenance of meiotic arrest in Atlantic croaker and zebrafish oocytes in vitro (Pang et al. 2008, Pang \& Thomas 2009, 2010). Although, significant increase in Gper, at both mRNA and protein level, has been reported earlier in late-vtellogenic oocytes (Pang \& Thomas 2010), currently no data is available to correlate the follicular growth and physiological level of $E_{2}$ either in circulation or in the ovary. As a result, we had to test effect of graded levels of $E_{2}(1,10,100$ and $1000 \mathrm{nM})$ on incidence of spontaneous maturation in defolliculated zebrafish oocytes. Present data demonstrate that $E_{2}$ priming could attenuate meiosis resumption (spontaneous maturation) in defolliculated post-vitellogenic oocytes (average diameter: 550-600 $\mu \mathrm{m}$ ) in dose- and duration-dependent manner. This is in agreement with earlier reports in zebrafish that showed a significant reduction in meiotic maturation due to $E_{2}$ at 20 and 100 nM (Pang \& Thomas 2009, 2010, Peyton \& Thomas 2011). Moreover, available information indicates that priming with $\mathrm{E}_{2}(20 \mathrm{nM})$ could effectively promote Gper expression and down-regulate mpra, but could exert its effect at protein levels (Gper or mPRa) only at $100 \mathrm{nM}$ concentration (Pang \& Thomas 2010). Earlier stimulation of zebrafish ovarian fragments as well as follicular cells in culture with $50 \mathrm{nM}$ of $\mathrm{E}_{2}$ has been shown to promote Ihcgr expression (Liu et al. 2011). Since earlier evidence suggests that $E_{2}$ at $100 \mathrm{nM}$ transactivates Egfr, promotes ERK $1 / 2$ phosphorylation and ensures prophase-I arrest in 
zebrafish oocytes (Peyton \& Thomas 2011), we hypothesized that degree of ERK1/2 phosphorylation could further serve as a means for selection of the dose of $E_{2}$. Present results reveal a dose-dependent increase in p-ERK1/2, the most effective being 10 and $100 \mathrm{nM}$ of $E_{2}$. Subsequently, two different doses of $E_{2}$ have been considered; while $10 \mathrm{nM}$ would be more physiological, overcoming the strong inhibitory effect even at $100 \mathrm{nM}$ of $E_{2}$ by maturational steroid and/or Igf1 could reasonably be more suitable to test our hypothesis.

While higher doses of DHP (30 and $300 \mathrm{nM}$ ) or Igf1 $(100 \mathrm{nM})$ promotes relatively higher percentage of oocytes undergoing GVBD compared to either $3 \mathrm{nM}$ of DHP- or $1 \mathrm{nM}$ of Igf1-treated groups respectively, present data demonstrate that priming with $\mathrm{E}_{2}$ attenuates maturational steroid (DHP)- as well as growth factor (Igf1)-induced OM in a dose-dependent manner. Since receptors are probably fully occupied at lower concentration, activation of signalling molecules for prolonged period due to higher concentration of ligands seems unlikely. Previously, participation of $\mathrm{MPR}$ in MIS stimulation of meiotic G2-M1 transition has been studied in great detail in several teleosts including zebrafish (Zhu et al. 2003, Pace \& Thomas 2005, Nagahama \& Yamashita 2008, Hanna \& Zhu 2011). Besides, earlier evidences have established that in addition to its role in positive regulation of $\mathrm{mPR}$ expression (Peng \& Thomas 2010), DHP at higher concentration can activate nuclear progestin receptor (nPR) to promote genomic mechanism for OM (Hanna \& Zhu 2011) or reduce Gper levels in the oocytes (Pang \& Thomas 2010). Alternatively, while relative abundance of igf2a, igf $2 b$ and igf 3 outweighs igf1 expression in the zebrafish ovary (Nelson \& Van Der Kraak 2010b, Li et al. 2015), recently it has been demonstrated that hCG stimulation promotes a robust increase in igf 3 expression and igf1 to a lesser extent prior to resumption of meiosis (Li et al. 2015). Besides, binding of Igf1 to insulin and/or insulin/lgf1 hybrid receptor may activate signalling molecules at higher magnitude (Belfiore et al. 2009), suggesting that activation of maturational steroid and Igfmediated signalling pathways together may engage in complex interaction for alleviating prophase arrest in this species. Although its strong negative influence on MISinduced maturational events in zebrafish and Atlantic croaker has been reported earlier (Pang et al. 2008, Pang \& Thomas 2009), $E_{2}$ inhibition of Igf1 action on meiosis resumption in defolliculated oocytes is being reported for the first time. Attenuation of both maturational steroid and growth-factor action on GVBD response possibly hints at the physiological relevance and universality of $E_{2}$ action in maintenance of prophase-I arrest. Given that the substantial amount of $E_{2}$ might be present in zebrafish ovary to support asynchronous mode of follicular growth, it would be interesting to examine the level of DHP and/or Igfs that could override strong negative influence of $E_{2}$ under physiological conditions in future.

Though gonadotropin (Lh) regulation of maturational steroid (progestins) synthesis prior to meiotic G2-M1 transition has been reported earlier (Khan \& Thomas 1999, Nagahama \& Yamashita 2008), a growing body of literature indicates involvement of local paracrine factors (e.g. activin and Igf family members) in mediating Lh action in teleosts ovary (Pang \& Ge 2002, Li et al. 2015). While Egf has recently been shown to act as an essential mediator of Lh action during mammalian OM (Park et al. 2004, Jamnongjit et al. 2005), presence of an active Igf system consisting of Igf ligands (Igf1, Igf2a, Igf $2 \mathrm{~b}$ and Igf3), receptors (Igf1ra and Igf1 rb) and Igf binding proteins have been reported earlier in zebrafish ovary (Nelson \& Van Der Kraak 2010b, Reinecke 2010, Li et al. 2015). Even though Igf1 could induce GVBD in mummichog and striped bass denuded oocytes or follicles when incubated with steroidogenesis inhibitors (Negatu et al. 1998, Weber \& Sullivan 2000), Igf2 has been shown to up-regulate synthesis of mPRa in southern flounder full-grown follicles (Picha et al. 2012). Moreover, available data indicate that while it requires almost $16 \mathrm{~h}$ for relatively high dose $(2 \mu \mathrm{m})$ of Igf3, Igf1 at $100 \mathrm{nM}$ could trigger a significant increase in meiotic maturation within the first $6 \mathrm{~h}$ in zebrafish full-grown and mid-vitellogenic follicles in vitro (Nelson \& Van Der Kraak 2010a, Li et al. 2015). Further, in vitro incubation of zebrafish ovarian follicles with Igf1 alone or in combination with hCG stimulates synthesis of DHP, but not $E_{2}$ (Nelson \& Van Der Kraak 2010a). These observations prompted us to use Igf 1 in the in vitro incubation study. Earlier, Igf1 has been shown to act as the most potent inducer of GVBD in red seabream, Pagrus major oocytes and more importantly in the presence of DHP; low doses of Igf1, Igf2 or insulin (which alone were ineffective) could promote GVBD response significantly (Kagawa et al. 1994). However, possibility of synergism between maturational steroidand Igf-mediated signalling cascades in alleviating $\mathrm{E}_{2}-$ mediated prophase arrest has not been investigated earlier. Present results show that co-treatment of DHP and Igf1 overcome the inhibitory effect of $E_{2}$ irrespective of the doses of $E_{2}$ used (10 and $100 \mathrm{nM}$ ). It has been established earlier that fish with synchronous ovarian development spawn once in a year and contain higher $E_{2}$ levels during the growth phase (vitellogenic phase) of the ovary with relatively much lower $\mathrm{E}_{2}$ concentration prior to spawning and ovulation (Specker \& Sullivan 1994, Khan \& Thomas 1999). However, in teleost like zebrafish, with asynchronous development of ovary contains higher level of circulatory $E_{2}$ for the maintenance of the growing vitellogenic oocytes throughout the year. Clearly the present data support the hypothesis that the synergism between the maturational steroid and local paracrine factor like Igf may play the pivotal role in overcoming the $\mathrm{E}_{2}$-mediated prophase-I arrest possibly 
in both these groups of fish. Moreover, results of the present study corroborate previous reports showing positive correlation between lgf 2 and $20 \beta-S$ in regulation of meiosis resumption in full-grown follicles of southern flounder, another teleost with asynchronous ovarian development (Picha et al. 2012). Taken together, these observations suggest that $\mathrm{E}_{2^{-}}$and DHP/lgf-mediated pathways, initiated at the oocyte surface, may engage in a complex dialogue in maintenance of prophase arrest and resumption of meiotic maturation respectively.

Data of the present study demonstrate that priming with anti-IGF-IR $\beta$ antibody attenuates Igf1, but not DHPinduced GVBD response. This provides evidence in favour of specificity of different receptor-mediated signalling cascades at the oocyte surface. While Igf1 receptor has been purified and high affinity lgf1 binding sites were demonstrated in amphibian oocytes as well as in carp ovary (Hainaut et al. 1991, Maestro et al. 1997), the possibility of all four Igf ligands acting through Igf1 $r$ in zebrafish oocytes cannot be ruled out at this moment since transcripts for two lgf1 receptor isoforms (igf1 ra and igf1rb) have been detected earlier (Nelson \& Van Der Kraak 2010b). Moreover, immunoblot analysis reveal that while Igf1 triggers a robust increase in Akt phosphorylation (Ser473), DHP stimulation also promotes a significant increase in Akt activation as early as $15 \mathrm{~min}$ of in vitro incubation. While it abrogates Igf1 action on OM, pharmacological inhibition of PI3K/Akt signalling could significantly delay DHP-induced GVBD response till $4-5 \mathrm{~h}$ of incubation. More importantly, Wrt in particular completely blocked $\mathrm{OM}$ up to $3 \mathrm{~h}$ indicating potential involvement and importance of PI3K/Akt signalling in DHP regulation of meiosis resumption in this species. Previously, inhibition of $\mathrm{Pl} 3 \mathrm{~K} / \mathrm{Akt}$ pathway has been shown to abrogate maturational steroid-induced GVBD response in Atlantic croaker, striped bass (Weber \& Sullivan 2001, Pace \& Thomas 2005) and starfish oocyte (Sadler \& Ruderman 1998). While microinjection of constitutively active Akt mRNA could induce meiosis in absence of 1-methyladenine, Akt is phosphorylated within a few minutes of 1-methyladenine addition, the natural MIS in this species (Okumura et al. 2002). Moreover, in mouse cumulus-free oocytes $\mathrm{p}$-Akt has been detected at $20 \mathrm{~min}$ and $\mathrm{Akt} / \mathrm{PKB}$ phosphorylation precedes onset of GVBD both in vivo and in vitro (Kalous et al. 2006). However, earlier evidence has established that PI3K inhibition either delays (Bagowski et al. 2001) or is without effect on progesterone-stimulated meiotic maturation in Xenopus, suggesting $\mathrm{Pl} 3 \mathrm{~K}$-mediated signalling might be an auxiliary pathway for progesterone action in this species (Andersen et al. 2003, Mood et al. 2004). Besides, insulin/IGF1 stimulation of meiotic G2-M1 transition in Xenopus and zebrafish oocytes has been shown to require Akt activation (Andersen et al. 2003, Das et al. 2013). Interestingly, pharmacological inhibition of PI3K could attenuate insulin/lgf1-mediated GVBD response in southern flounder and catfish follicle-enclosed oocytes (Picha et al. 2012, Hajra et al. 2016). Although growth factor-mediated Akt activation requires receptor tyrosine kinase activation, MIS regulation of Akt phosphorylation may primarily involve activation of GPCR in oocytes (Sadler \& Ruderman 1998, Pace \& Thomas 2005). Besides, rapid activation of Akt could be triggered through the $\mathrm{G} \beta \gamma$ subunit of heterotrimeric G-protein that might dissociate upon ligand (DHP) binding to membrane GPCR ( $\mathrm{mPR}$ ) followed by the activation of class 1B PI3K (Stephens et al. 1997).

Moreover, present data reveal that while Ac inhibition alone is sufficient to promote meiosis progression, forced elevation of intra-oocyte cAMP abrogates both DHP- and Igf1-induced GVBD response in a dose-dependent manner. Previously, treatment of Atlantic croaker ovarian membranes by GPER agonist has been shown to increase Ac activity and also reversed the downregulation of Ac activity by 20ß-S (Pang et al. 2008). While stimulation with catecholestrogen has been shown to down-regulate intra-oocyte cAMP level (Chourasia et al. 2015), MIS action, presumably through mPRa, attenuates Ac activity and intra-oocyte cAMP level by activating the inhibitory $\mathrm{G}$ protein, $\mathrm{G} \alpha_{\mathrm{i}}$ (Zhu et al. 2003). Earlier we have reported that PI3K/Akt pathway is indispensable for insulin-induced meiotic maturation in denuded zebrafish oocyte, where PDE3 might act as possible a down-stream target (Das et al. 2013). Although involvement of a cAMP-independent $\mathrm{PI} 3 \mathrm{~K} / \mathrm{Akt}$ signalling cascade has been proposed in starfish, striped bass and Atlantic croaker during MISinduced maturation (Sadler \& Ruderman 1998, Weber \& Sullivan 2001, Pace \& Thomas 2005), high cAMP could block insulin-induced GVBD response in zebrafish oocytes (Maitra et al. 2014). Taken together these data suggest that CAMP-mediated signalling might have strong negative influence on both maturational steroid and Igf regulation of meiotic $\mathrm{G} 2-\mathrm{M} 1$ transition in zebrafish oocytes.

On the basis of the preceding, it was reasoned that DHP and Igf1-mediated signalling events might have additive influence and possibly converge at some point to down-regulate a factor which when active ensures prophase arrest. Previously, high cAMP has been shown to activate PKA which subsequently block synthesis of cyclin B and resumption of meiosis (Conti et al. 2002). Moreover, potential antagonism between cAMP and receptor tyrosine kinase-regulated signalling axes is evident from the fact that high cAMP/PKA could successfully abrogate insulin-mediated MEK/MAPK signalling axis in zebrafish oocytes (Maitra et al. 2014). Taking cue from these reports, we reasoned involvement of PKA in the cross-talk between $E_{2}$, MIS and Igfmediated signalling events that may act in tandem to regulate prophase arrest and resumption of meiotic maturation in this species. Present data demonstrate that $\mathrm{E}_{2}$ could significantly promote PKA phosphorylation 
(activation). Though low dose of either DHP or Igf1 alone is sufficient to promote p-PKAc dephosphorylation (inactivation) almost to the basal level and marginal increase in GVBD response, incorporation of $E_{2}$ (10 and $100 \mathrm{nM}$ ) in the culture medium could reverse both these effects. On the contrary, co-treatment with DHP and Igf1 (at comparable dose) could successfully abrogate $\mathrm{E}_{2}$-mediated PKA phosphorylation concomitant with accelerated GVBD response. Although DHP- or insulin-mediated down-regulation of intra-oocyte PKA activity has been reported earlier in perch, Anabas testudineus (Khan \& Maitra 2013) and zebrafish (Maitra et al. 2014), the present data could successfully demonstrate potential synergism between maturational steroid and Igf-mediated signalling in PKA inhibition prior to the release of prophase-I arrest and final OM.

Most importantly, participation of both DHP- and Igfmediated signalling events in the maturation process under physiological condition is further evident from the fact that; i) heightened expression of igf1 and igf3; ii) elevated Tyr phosphorylation of anti-lgf1 $\mathrm{r}$ immunoprecipitated protein; iii) mPRa expression at protein and possibly at mRNA level and iv) robust increase in Akt activation congruent with down-regulation of phosphoPKA (inhibition) in follicular lysates at $0500 \mathrm{~h}(-1 \mathrm{~h}$ before morning light signals on) correlates well with substantial increase in percentage of oocytes undergoing GVBD between 0500 and 0600 h, i.e., prior to ovulation in vivo. While $\mathrm{mPRa}$ as well as Igf1 $\mathrm{r}$ have been identified in zebrafish oocyte (Nelson \& Van Der Kraak 2010b, Hanna \& Zhu 2011), a close association between the putative $\mathrm{mPRa}$ and $\mathrm{OM}$ in seatrout and zebrafish has been indicated earlier as rapid increase in receptor levels occurred in fully grown oocytes in vitro during hCGinduced GVBD (Zhu et al. 2003, Hanna \& Zhu 2011). Besides, involvement of Igf1r in hCG-induced meiotic maturation has been demonstrated in zebrafish oocytes (Li et al. 2015). Further, involvement of DHP and/or Igf1 in activation of down-stream signalling molecules like Akt phosphorylation and PKA down-regulation, during the natural course of GVBD response, provides evidence in favour of synergistic action between MIS and Igf1.

While priming with anti-IGF1R antibody in vitro fails to inhibit DHP stimulation of meiotic maturation in denuded oocytes, present data provide evidence in favour of functional relevance of Igf1r (through Tyr phosphorylation) in Igf1- and/or Igf3-mediated maturation process in full-grown follicles in vivo. Although there has been significant increase in both Igf3 as well as Igf1 transcripts just prior to onset of ovulation, it is pertinent to reflect upon which form of $\operatorname{Igf}(\mathrm{s})$ is either necessary or essential for releasing prophase-I arrest in zebrafish. Interestingly, all four Igf ligands (Igf1, Igf2a, Igf2b and Igf3) have been shown to induce meiosis resumption with varying degrees of potentialities in zebrafish oocytes (Nelson \& Van Der Kraak 2010a, $\mathrm{Li}$ et al. 2015). Although a robust increase in igf3 expression has been reported earlier (Li et al. 2015), we observed elevated expression of igf1 due to hCG stimulation (P Ghosh, D Das \& S Maitra, unpublished observation). More importantly, available information indicates that while Igf1 at low dose $(100 \mathrm{nM})$ could trigger a significant increase in meiosis resumption within $6 \mathrm{~h}$, priming with either Igf2a, Igf $2 \mathrm{~b}$ or Igf3 at apparently supra-physiological concentration $(2 \mu \mathrm{M})$, promotes GVBD response in $\sim 60-80 \%$ of full-grown zebrafish follicle-enclosed oocytes after $17 \mathrm{~h}$ ( $\mathrm{Li}$ et al. 2015). Moreover, a dose-dependent (from $0.2 \mathrm{nM}$ to $2 \mu \mathrm{M})$ increase in Igf3-induced OM has been demonstrated in zebrafish (Li et al. 2011), suggesting the

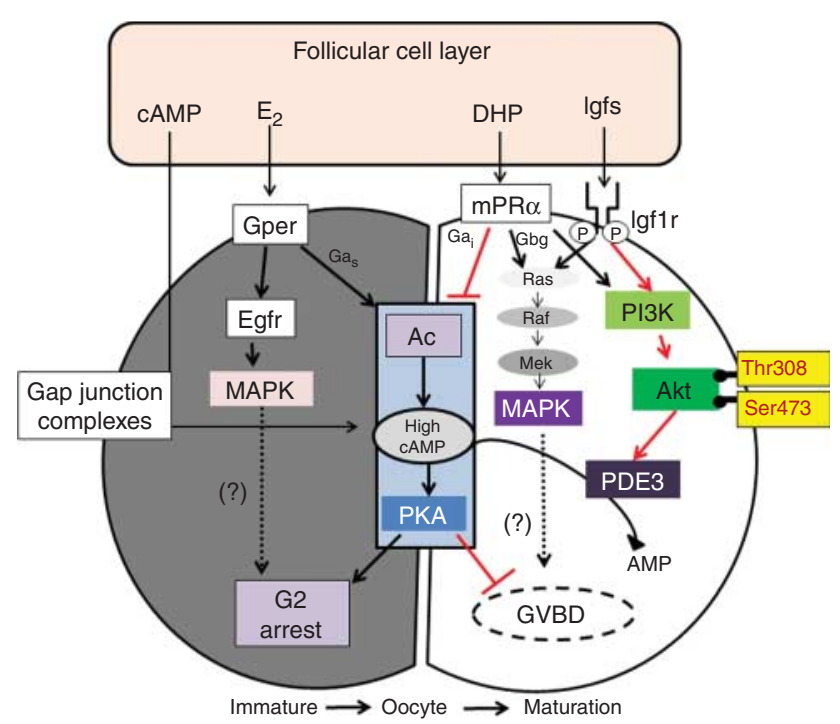

Figure 7 Proposed model behind maintenance of prophase arrest and how DHP- and Igf-mediated signalling events may act synergistically to overcome $E_{2}$ inhibition of meiosis resumption in zebrafish oocytes. Pioneering work by Pang \& Thomas (2010) and Peyton \& Thomas (2011) have demonstrated earlier that in addition to its role in Ac activation to synthesize cAMP, binding of $E_{2}$ to Gper at oocyte surface transactivate Egfr to induce MAPK activation; both of which are involved in the maintenance of $E_{2}$-mediated prophase-I arrest. Conversely, DHP action at the oocyte surface, possibly through mPRa, activates $\mathrm{Ga}_{\mathrm{i}}$, which in turn attenuates Ac activity and prevents cAMP production (Zhu et al. 2003, Pang \& Thomas 2010). While DHP stimulation promotes Akt phosphorylation (albeit in lower amount), Igf1 stimulation triggers a rapid and strong activation of PI3K/Akt/PDE3 cascade (Das et al. 2013) allowing breakdown of intra-oocyte cAMP. Thus inhibition of cAMP synthesis coupled with a rapid clearance of cAMP (that could possibly come through gap-junction complexes) leads to down regulation of PKA; a pre-requisite for resumption of meiosis (Conti et al. 2002, Nagahama \& Yamashita 2008).

In conclusion, the physiological relevance of $\mathrm{E}_{2}$-mediated meiotic arrest and synergism between steroid- and growth factor-mediated signalling events allowing meiosis resumption might have evolved over time for better regulation of reproductive function necessary for successful perpetuation of a species. Dotted lines represent MAPKmediated signalling pathway, activation of which represent diametrically opposite outcome in species-specific manner (Kajiura-Kobayashi et al. 2000, Pace \& Thomas 2005, Peyton \& Thomas 2011, Khan \& Maitra 2013, Maitra et al. 2014). 
required concentration of Igf3 is much higher to saturate Igf $r$, the possible physiological receptor of Igf3. Further, Igf3, Igf2a and Igf $2 \mathrm{~b}$ at $2 \mu \mathrm{m}$ concentration has been reported to exhibit GVBD response up to $60 \%$ of denuded oocytes after $4 \mathrm{~h}$ (Li et al. 2015). However, in the present study at the same time point we find that Igf1 at $10 \mathrm{nM}$ is sufficient to promote meiosis resumption in more than $75 \%$ oocytes. Taken together these results tempted us to believe that though mRNA abundance of Igf1 is much lower in the zebrafish ovary, Igf1 could be the possible isoform that actually helps in promoting meiosis resumption since the receptor isoform involved in mediating all Igfs function is essentially the same one, i.e., Igf1r. However, in the future it would be interesting to examine the specificity as well as the affinity of binding between various Igf ligands (Igf $2 a$, Igf $2 b$ and Igf3) and Igf1 $r$ at the oocyte surface. Clearly, proteomic analysis of $\operatorname{lgf}(\mathrm{s})$ expressed prior to re-initiation of meiotic G2-M1 transition under physiological condition, as well as selective knock out of individual Igf ligands or targeted knock down using morpholino in vitro may provide significant insight to determining participation of specific Igf isoforms(s) or their overlapping action in the maturational process in zebrafish.

Finally, the model in Fig. 7 illustrates the mechanism behind release of $E_{2}$-mediated prophase arrest in zebrafish oocyte, most importantly synergism between $\mathrm{DHP}$ and Igf1 during G2-M1 progression. As reported earlier, cAMP from follicular cells through gap junction (Nagahama \& Yamashita 2008) or $E_{2}$ action at the oocyte surface through Gper1/G $\alpha_{s} /$ Ac/cAMP cascade (Pang \& Thomas 2010) promotes PKA activation and ensures prophase-I arrest (Conti et al. 2002). Besides, transactivation of Egfr system by Gper1 could stimulate MAPK activation (Peyton \& Thomas 2011).

Although the molecular mechanism is not yet clearly understood, $E_{2}$-mediated activation of MAPK might have strong negative influence on meiosis progression in teleost oocytes. While participation of $\mathrm{G} \beta \gamma$ subunit of heterotrimeric G-protein has been implicated in DHP stimulation of PI3K/Akt and MAPK activation (Hanna et al. 2006), down regulation of cAMP/PKA pathway involves $\mathrm{mPRa} / \mathrm{G} \alpha \mathrm{i}$ - mediated attenuation of Ac (Zhu et al. 2003). On the other hand, Igf1 action at oocyte surface requires participation of Igf1 $r$, and triggers rapid activation of Akt-mediated signalling cascade in denuded oocytes in vitro. Earlier we demonstrated that recombinant human insulin (rh-insulin) could promote MAPK activation, potentially through Ras/Raf/Mek cascade (Maitra et al. 2014), as well as PI3K/Akt/PDE3 signalling in denuded zebrafish oocyte, allowing further reduction in CAMP/PKA and promoting OM (Das et al. 2013). Although it could attenuate rh-insulin-mediated GVBD, MEK inhibition failed to prevent DHP action on OM (D Das, P Ghosh, S Pal, P Nath, S Hajra \& S Maitra 2015, unpublished observation), suggesting contrary to its involvement observed earlier in A. testudineus (Khan
\& Maitra 2013), MAPK activation might have marginal influence in lifting prophase arrest in zebrafish oocyte.

Interestingly, significant increase in Akt phosphorylation was observed in Igf1 as well as DHP-induced oocytes and pharmacological inhibition of PI3K/Akt abrogated Igf1-induced GVBD and attenuates DHP action till $4-5 \mathrm{~h}$ of incubation. Moreover, high intraoocyte cAMP attenuates both DHP and Igf1-mediated GVBD and co-stimulation with DHP and Igf1 at physiological concentration, but not alone, could effectively reverse $E_{2}$ action on PKA activation and G2 arrest. These observations provide a basis for integration between two disparate signalling strategies at the molecular level. Interestingly, apparent increase in $\mathrm{mPRa}$ at both mRNA and protein level as well as elevated expression of igf1 and igf3 coupled with IGF1R phosphorylation and significant increase in Akt activation (phosphorylated at Ser473 and Thr308) in maturing follicles in vivo potentially hint at participation and functional relevance of both DHP and Igf-mediated signalling prior to natural course of $\mathrm{OM}$ in this species.

\section{Declaration of interest}

The authors declare that there is no conflict of interest that could be perceived as prejudicing the impartiality of the research reported.

\section{Funding}

The work is supported by Department of Biotechnology (grant number BT/29/NE/TBP/2010) and University Grants Commission (F. no. 39-681/2010 (SR)) to S Maitra and financial assistance to D Das from INSPIRE Program, Department of Science and Technology, New Delhi, Government of India.

\section{Acknowledgements}

The authors express their sincere thanks to the reviewers and editorial board members for their valuable suggestions and critical review of the manuscript. Technical assistance was provided by Mr Sudip Hajra, Ms Pritha Ghosh, Ms Poulomi Nath and by Dr Disha Banerjee from Thermo Fisher, India for qRT-PCR. The authors are also thankful to Head, Department of Zoology, Visva-Bharati University, Santiniketan, India for providing instrument facility.

\section{References}

Andersen CB, Sakaue H, Nedachi T, Kovasina KS, Clayberger C, Conti M \& Roth RA 2003 Protein kinase B/Akt is essential for the insulin but not progesterone stimulated resumption of meiosis in Xenopus oocyte. Biochemical Journal 369 227-238. (doi:10.1042/bj20021243)

Bagowski CP, Myers JW \& Ferrell JE Jr 2001 The classical progesterone receptor associates with p42 MAPK and is involved in phosphatidylinositol 3-kinase signaling in Xenopus oocytes. Journal of Biological Chemistry 276 37708-37714. (doi:10.1074/jbc.M104582200) 
Belfiore A, Frasca F, Pandini G, Sciacca L \& Vigneri R 2009 Insulin receptor isoforms and insulin receptor/insulin-like growth factor receptor hybrids in physiology and disease. Endocrine Reviews 30 586-623. (doi:10. 1210/er.2008-0047)

Chourasia TK, Pang Y \& Thomas P 2015 The catecholestrogen, 2-hydroxyestradiol-17 $\beta$, acts as a $G$ protein-coupled estrogen receptor 1 (GPER/GPR30) antagonist to promote the resumption of meiosis in zebrafish oocytes. Biology of Reproduction 92 69. (doi:10.1095/ biolreprod.114.125674)

Clelland E \& Peng C 2009 Endocrine/paracrine control of zebrafish ovarian development. Molecular and Cellular Endocrinology 312 42-52. (doi:10.1016/j.mce.2009.04.009)

Conti M, Andersen CB, Richard F, Mehats C, Chun S-Y, Horner K, Jin C \& Tsafriri A 2002 Role of cyclic nucleotide signaling in oocyte maturation. Molecular and Cellular Endocrinology 187 153-159. (doi:10.1016/ S0303-7207(01)00686-4)

Das D, Khan PP \& Maitra S 2013 Participation of PI3-kinase/Akt signalling in insulin stimulation of p34cdc2 activation in zebrafish oocyte: phosphodiesterase 3 as a potential down-stream target. Molecular and Cellular Endocrinology 374 46-55. (doi:10.1016/j.mce.2013.04.007)

DeManno DA \& Goetz FW 1987 Steroid-induced final maturation in brook trout (Salvelinus fontinalis) oocytes in vitro: the effects of forskolin and phosphodiesterase inhibitors. Biology of Reproduction 36 1321-1332. (doi:10.1095/biolreprod36.5.1321)

Haider S \& Baqri SS 2002 Role of cyclic AMP-dependent protein kinase in oocyte maturation of the catfish, Clarias batrachus. Journal of Experimental Zoology 292 587-593. (doi:10.1002/jez.10102)

Hainaut P, Kowalski A, Giorgetti S, Baron V \& Van Obberghen E 1991 Insulin and insulin-like growth factor-1 (IGF-1) receptors in Xenopus laevis oocyte. Comparison with insulin receptors from liver and muscle. Biochemical Journal 273 673-678. (doi:10.1042/bj2730673)

Hajra S, Das D, Ghosh P, Pal S, Nath P \& Maitra S 2016 Regulation of recombinant human insulin-induced maturational events in Clarias batrachus (L.) oocytes in vitro. Zygote. In Press. (doi:10.1017/ S096719 9415000015)

Hanna RN \& Zhu Y 2011 Controls of meiotic signaling by membrane or nuclear progestin receptor in zebrafish follicle enclosed oocytes. Molecular and Cellular Endocrinology 337 80-88. (doi:10.1016/j.mce. 2011.02.004)

Hanna R, Pang Y, Thomas P \& Zhu Y 2006 Cell surface expression, progestin binding and rapid nongenomic signaling of zebrafish membrane progestin receptors $\alpha$ and $\beta$ in transfected cells. Journal of Endocrinology 190 247-260. (doi:10.1677/joe.1.06694)

Hirai T, Yamashita M, Yoshikuni M, Tokomoto T, Kajiura H, Sakai N \& Nagahama Y 1992 Isolation and characterization of goldfish cdk2, a cognate variant of the cell cycle regulator cdc2. Developmental Biology 152 113-120. (doi:10.1016/0012-1606(92)90161-9)

Jalabert B 1975 Modulation of 17- $\alpha$-hydroxy-20ß-dihydroprogesterone or gonadotropic extract activity on the in vitro intrafollicular maturation of rainbow trout (Salmo gairdnerii) oocytes by various steroids lacking maturing activity. Comptes Rendus Hebdomadaires Des Séances De I'Académie Des Sciences. Série D: Sciences Naturelles 281 811-814.

Jamnongjit M, Gill A \& Hammes SR 2005 Epidermal growth factor receptor signaling is required for normal ovarian steroidogenesis and oocyte maturation. PNAS 102 16257-16262. (doi:10.1073/pnas.0508521102)

Kagawa H, Kobayashi M, Hasegawa Y \& Aida K 1994 Insulin and insulinlike growth factors I and II induce final maturation of oocytes of red seabream, Pagrus major, in vitro. General and Comparative Endocrinology 95 293-300. (doi:10.1006/gcen.1994.1126)

Kagawa H, Moriyama S \& Kawauchi H 1995 Immunocytochemical localization of IGF-I in the ovary of the red seabream, Pagrus major. General and Comparative Endocrinology 99 307-315. (doi:10.1006/ gcen.1995.1114)

Kajiura-Kobayashi H, Yoshida N, Sagata N, Yamashita M \& Nagahama Y 2000 The Mos/MAPK pathway is involved in metaphase II arrest as a cytostatic factor but is neither necessary nor sufficient for initiating oocyte maturation in goldfish. Development Genes and Evolution 210 416-425. (doi:10.1007/s004270000083)

Kalous J, Solc P, Baran V, Kubelka M, Schultz RM \& Motlik J 2006 PKB/AKT is involved in resumption of meiosis in mouse oocytes. Biology of the Cell 98 111-123. (doi:10.1042/BC20050020)
Khan PP \& Maitra S 2013 Participation of cAMP-dependent protein kinase and MAP kinase pathways during Anabas testudineus oocyte maturation. General and Comparative Endocrinology 181 88-97. (doi:10.1016/ j.ygcen.2012.10.016)

Khan IA \& Thomas P 1999 Ovarian cycle, teleost fish. In Encyclopedia of Reproduction, vol 3, pp 552-564. Eds: E Knobil \& JD Neill. San Diego, CA: Academic Press.

Kishida M \& Callard GV 2001 Distinct cytochrome P450 aromatase isoforms in zebrafish (Danio rerio) brain and ovary are differentially programmed and estrogen regulated during early development. Endocrinology 142 740-750. (doi:10.1210/endo.142.2.7928)

Kondo T, Yanagawa T, Yoshida N \& Yamashita M 1997 Introduction of cyclin B induces activation of the maturation-promoting factor and breakdown of germinal vesicle in growing zebrafish oocytes unresponsive to the maturation inducing hormone. Developmental Biology 190 142-152. (doi:10.1006/dbio.1997.8673)

Lessman CM \& Kavumpurath S 1984 Cytological analysis of nuclear migration and dissolution during steroid-induced meiotic maturation in vitro of follicle-enclosed oocytes of the goldfish (Carassius auratus). Gamete Research 10 21-29. (doi:10.1002/mrd.1120100104)

Li J, Liu Z, Wang D \& Cheng CHK 2011 Insulin-like growth factor 3 is involved in the oocyte maturation in zebrafish. Biology of Reproduction 84 473-486. (doi:10.1095/biolreprod.110.086363)

Li J, Chu L, Sun X, Liu Y \& Cheng CHK 2015 Igfs mediate the action of luteinizing hormone on oocyte maturation in zebrafish. Molecular Endocrinology 29 373-383. (doi:10.1210/me.2014-1218)

Liu K-C, Lin S-W \& Ge W 2011 Differential regulation of gonadotropin receptors (fshr and Ihcgr) by estradiol in the zebrafish ovary involves nuclear estrogen receptors that are likely located on the plasma membrane. Endocrinology 152 4418-4430. (doi:10.1210/en.2011-1065)

Livak KJ \& Schmittgen TD 2001 Analysis of relative gene expression data using real-time quantitative PCR and the $2(-$ Delta Delta $C(\mathrm{~T}))$ method. Methods 25 402-408. (doi:10.1006/meth.2001.1262)

Lowry OH, Rosebrough NJ, Farr AE \& Randall RJ 1951 Protein measurement with folin phenol reagent. Journal of Biological Chemistry 193 265-275.

Maestro MA, Mendez E, Pairrizas M \& Gutierrez J 1997 Characterization of insulin and insulin-like growth factor-I ovarian receptors during the reproductive cycle of carp (Cyprinus carpio). Biology of Reproduction $\mathbf{5 6}$ 1126-1132. (doi:10.1095/biolreprod56.5.1126)

Maitra S, Das D, Ghosh P, Hajra S, Roy SS \& Bhattacharya S 2014 High cAMP attenuation of insulin-stimulated meiotic G2-M1 transition in zebrafish oocytes: interaction between the cAMP-dependent protein kinase (PKA) and the MAPK3/1 pathways. Molecular and Cellular Endocrinology 393 109-119. (doi:10.1016/j.mce.2014.06.008)

Maures T, Chan SJ, Xu B, Sun H, Ding J \& Duan C 2002 Structural, biochemical, and expression analysis of two distinct insulin-like growth factor I receptors and their ligands in zebrafish. Endocrinology 143 1858-1871. (doi:10.1210/endo.143.5.8768)

Mood K, Bong YS, Lee HS, Ishimura A \& Daar IO 2004 Contribution of JNK, Mek, Mos and PI-3K signaling to GVBD in Xenopus oocytes. Cellular Signalling 16 631-642. (doi:10.1016/j.cellsig.2003.10.005)

Moore MJ, Kanter JR, Jones KC \& Taylor SS 2002 Phosphorylation of the catalytic subunit of protein kinase A. Autophosphorylation versus phosphorylation by phosphoinositide-dependent kinase-1. Journal of Biological Chemistry 277 47878-47884. (doi:10.1074/jbc. M204970200)

Nagahama Y \& Yamashita M 2008 Regulation of oocyte maturation in fish. Development, Growth \& Differentiation 50 S195-S219. (doi:10.1111/ j.1440-169X.2008.01019.x)

Negatu Z, Hsiao SM \& Wallace RA 1998 Effects of insulin-like growth factor-I on final oocyte maturation and steroid production in Fundulus heteroclitus. Fish Physiology and Biochemistry 19 13-21. (doi:10.1023/ A:1007777926238)

Nelson SN \& Van Der Kraak G 2010a The role of the insulin-like growth factor (IGF) system in zebrafish (Danio rerio) ovarian development. General and Comparative Endocrinology 168 103-110. (doi:10.1016/ j.ygcen.2010.04.021)

Nelson SN \& Van Der Kraak G 2010b Characterization and regulation of the insulin-like growth factor (IGF) system in the zebrafish (Danio rerio) ovary. General and Comparative Endocrinology 168 111-120. (doi:10. 1016/j.ygcen.2010.04.020) 
Okumura E, Fukuhara T, Yoshida H, Hanada Si S, Kozutsumi R, Mori M, Tachibana K \& Kishimoto T 2002 Akt inhibits Myt1 in the signaling pathway that leads to meiotic G2/M-phase transition. Nature Cell Biology 4 111-116. (doi:10.1038/ncb741)

Pace MC \& Thomas P 2005 Steroid-induced oocyte maturation in Atlantic croaker (Micropogonias undulatus) is dependent on activation of the phosphatidylinositol 3-kinase/Akt signal transduction pathway. Biology of Reproduction 73 988-996. (doi:10.1095/biolreprod.105. 041400)

Pang Y \& Ge W 2002 Gonadotropin regulation of activin $\beta A$ and activin type IIA receptor expression in the ovarian follicle cells of the zebrafish, Danio rerio. Molecular and Cellular Endocrinology 188 195-205. (doi:10.1016/S0303-7207(01)00719-5)

Pang Y \& Thomas P 2009 Involvement of estradiol-17 $\beta$ and its membrane receptor. G protein coupled receptor 30 (GPR30) in regulation of oocyte maturation in zebrafish, Danio rerio. General and Comparative Endocrinology 161 58-61. (doi:10.1016/j.ygcen.2008.10.003)

Pang Y \& Thomas P 2010 Role of G protein-coupled estrogen receptor 1, GPER, in inhibition of oocyte maturation by endogenous estrogens in zebrafish. Developmental Biology 342 194-206. (doi:10.1016/j.ydbio. 2010.03.027)

Pang Y, Dong J \& Thomas P 2008 Estrogen signaling characteristics of Atlantic croaker G protein-coupled receptor 30 (GPR30) and evidence it is involved in maintenance of oocyte meiotic arrest. Endocrinology 149 3410-3426. (doi:10.1210/en.2007-1663)

Park JY, Su YQ, Ariga M, Law E, Jin SL \& Conti M 2004 EGF-like growth factors as mediators of $\mathbf{L H}$ action in the ovulatory follicle. Science $\mathbf{3 0 3}$ 682-684. (doi:10.1126/science.1092463)

Patiño R \& Kagawa H 1999 Regulation of gap junctions and oocyte maturational competence by gonadotropin and insulin-like growth factor-I in ovarian follicles of red seabream. General and Comparative Endocrinology 115 454-462. (doi:10.1006/gcen. 1999.7341)

Perrot V, Moiseeva EB, Gozes Y, Chan SJ \& Funkenstein B 2000 Insulin-like growth factor receptors and their ligands in gonads of a hermaphroditic species, the gilthead seabream (Sparus aurata): expression and cellular localization. Biology of Reproduction 6 229-241. (doi:10.1095/biolreprod63.1.229)

Peyton C \& Thomas P 2011 Involvement of epidermal growth factor receptor signalling in estrogen inhibition of oocyte maturation mediated through the $G$ protein-coupled estrogen receptor (Gper) in zebrafish (Danio rerio). Biology of Reproduction 85 42-50. (doi:10.1095/ biolreprod.110.088765)

Picha ME, Shi B \& Thomas P 2012 Dual role of IGF-II in oocyte maturation in southern flounder Paralichthys lethostigma: up-regulation of mPRa and resumption of meiosis. General and Comparative Endocrinology 177 220-230. (doi:10.1016/j.ygcen.2012.04.017)

Pikulkaew S, De Nadai A, Belvedere P, Colombo L \& Dalla Valle L 2010 Expression analysis of steroid hormone receptor mRNAs during zebrafish embryogenesis. General and Comparative Endocrinology 165 215-220. (doi:10.1016/j.ygcen.2009.06.024)

Reinecke M 2010 Insulin-like growth factors and fish reproduction. Biology of Reproduction 82 656-661. (doi:10.1095/biolreprod.109. 080093)
Sadler KC \& Ruderman JV 1998 Components of the signaling pathway linking the 1-methyladenine receptor to MPF activation and maturation in starfish oocytes. Developmental Biology 197 25-38. (doi:10.1006/ dbio.1998.8869)

Sarkar S, Bhattacharya D, Juin SK \& Nath P 2014 Biological properties of Indian walking catfish (Clarias batrachus) (L.) gonadotropins in female reproduction. Fish Physiology and Biochemistry 40 1849-1861. (doi:10. 1007/s10695-014-9973-0)

Schmid AC, Naef E, Kloas W \& Reinecke M 1999 IGF-I and IGF-II in the ovary of a bony fish Oreochromis mossambicus, the tilapia: in situ hybridisation, immunohistochemical localization, northern blot and cDNA sequences. Molecular and Cellular Endocrinology 156 141-149. (doi:10.1016/S0303-7207(99)00131-8)

Schmitt A \& Nebreda AR 2002 Signalling pathways in oocyte maturation. Journal of Cell Science 115 2457-2459.

Specker JL \& Sullivan CV 1994 Vitellogenesis in fishes: status and perspectives. In Perspectives in Comparative Endocrinology, pp 304-315. Eds KG Davey, RE Peter\& SS Tobe. Ottawa, ON, Canada: National Research Council of Canada.

Stephens LR, Eguinoa A, Erdjument-Bromage $H$, Lui $M$, Cooke $F$, Coadwell J, Smrcka AS, Thelen M, Cadwallader K, Tempst P et al. 1997 The G $\beta \gamma$ sensitivity of a PI3K is dependent upon a tightly associated adaptor, p101. Cell 89 105-114. (doi:10.1016/S0092-8674(00)80187-7)

Sundararaj BI, Goswami SV \& Lamba V 1979 Some aspects of oocyte maturation in catfish. Journal of Steroid Biochemistry 11 701-707. (doi:10.1016/0022-4731(79)90003-7)

Tokumoto T, Tokumoto M, Horiguchi R, Ishikawa K \& Nagahama Y 2004 Diethylstilbestrol induces fish oocyte maturation. PNAS 101 3686-3690. (doi:10.1073/pnas.0400072101)

Wang DS, Jiao B, Hu C, Huang X, Liu Z \& Cheng CH 2008 Discovery of a gonad-specific IGF subtype in teleost. Biochemical and Biophysical Research Communications 367 336-341. (doi:10.1016/j.bbrc.2007.12.136)

Weber GM \& Sullivan CV 2000 Effects of insulin-like growth factor-I on in vitro final oocyte maturation and ovarian steroidogenesis in striped bass, Morone saxatilis. Biology of Reproduction 63 1049-1057. (doi:10.1095/biolreprod63.4.1049)

Weber GM \& Sullivan CV 2001 In vitro hormone induction of final oocyte maturation in striped bass (Morone saxitallis) follicles is inhibited by blockers of phosphatidylinositol 3-kinase activity. Comparative Biochemistry and Physiology. Part B, Biochemistry \& Molecular Biology 129 467-473. (doi:10.1016/S1096-4959(01)00349-9)

Westerfield M 2000 In The Zebrafish Book: A Guide for the Laboratory Use of Zebrafish (Danio rerio). 4th ed. Eugene, OR, USA: University of Oregon Press.

Zhu Y, Rice CD, Pang Y, Pace M \& Thomas P 2003 Cloning, expression, and characterization of a membrane progestin receptor and evidence it is an intermediary in meiotic maturation of fish oocytes. PNAS $\mathbf{1 0 0}$ 2231-2236. (doi:10.1073/pnas.0336132100)

Received 23 April 2015

First decision 18 June 2015

Revised manuscript received 4 October 2015

Accepted 22 October 2015 